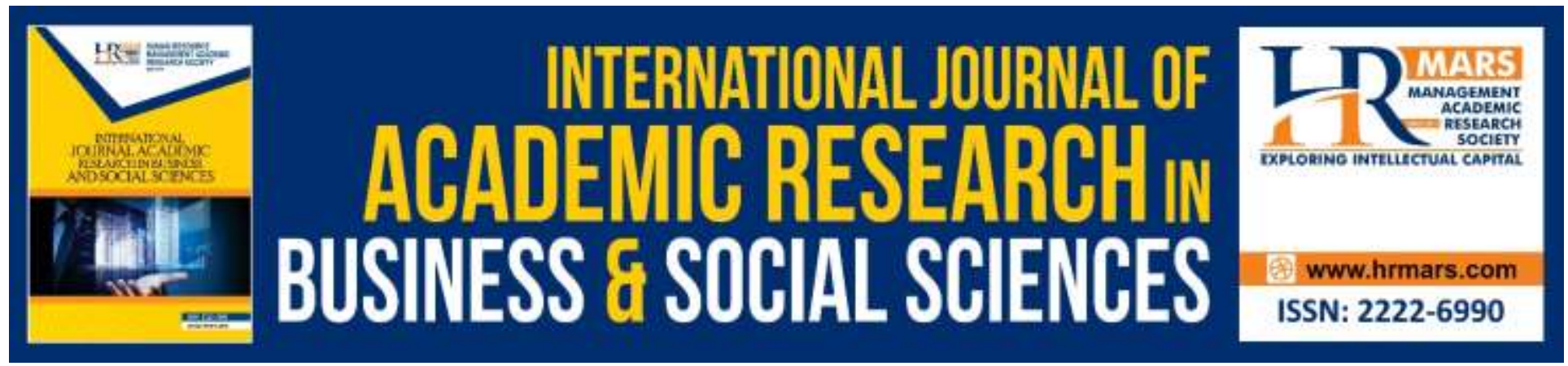

\title{
Searching For an Ideal Post Graduate Supervisor: Exploring Malaysian Students' Experience towards Supervisory Relationship
}

Siti Fairuz Murshid, Ismi Arif Ismail, Roselan Baki

To Link this Article: http://dx.doi.org/10.6007/IJARBSS/v9-i11/6556

DOI: 10.6007/IJARBSS/v9-i11/6556

Received: 10 October 2019, Revised: 30 October 2019, Accepted: 03 November 2019

Published Online: 24 November 2019

In-Text Citation: (Murshid, Ismail, \& Baki, 2019)

To Cite this Article: Murshid, S. F., Ismail, I. A., Baki, R. (2019). Searching For an Ideal Post Graduate Supervisor: Exploring Malaysian Students' Experience towards Supervisory Relationship. International Journal of Academic Research in Business and Social Sciences, 9(11), 384-399.

Copyright: (C) 2019 The Author(s)

Published by Human Resource Management Academic Research Society (www.hrmars.com)

This article is published under the Creative Commons Attribution (CC BY 4.0) license. Anyone may reproduce, distribute, translate and create derivative works of this article (for both commercial and non-commercial purposes), subject to full attribution to the original publication and authors. The full terms of this license may be seen at: http://creativecommons.org/licences/by/4.0/legalcode

Vol. 9, No. 11, 2019, Pg. 384 - 399

Full Terms \& Conditions of access and use can be found at http://hrmars.com/index.php/pages/detail/publication-ethics 


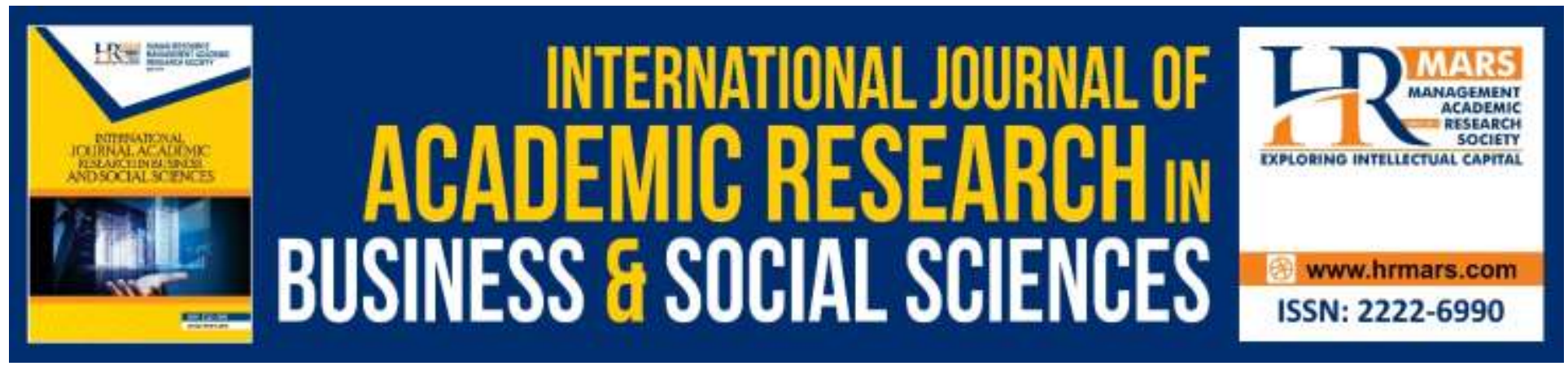

\title{
Searching For an Ideal Post Graduate Supervisor: Exploring Malaysian Students' Experience towards Supervisory Relationship
}

\author{
Siti Fairuz Murshid, Ismi Arif Ismail, Roselan Baki \\ Faculty of Educational Studies, Universiti Putra Malaysia, Serdang, Selangor Darul Ehsan, \\ Malaysia \\ Email: ct5ruz2105@gmail.com, ismilina@gmail.com
}

\begin{abstract}
This study explores the experience of establishing a supervisory relationship between postgraduates and supervisors from the perspective of four first semester graduate students in one of Malaysia public university. This study uses a qualitative case study design. Data are obtained through semi-structured interviews and document analysis. The findings of this research revealed that the adjustment aspect of alignment of tendency and interests, confidence, meaningful communication, high reliability, mutual respect and punctuality were the key determinants of establishing a positive supervisory relationship between post graduates and supervisors. This study also demonstrated that a healthy rapport between post graduate students and supervisors really do support their research and learning journey. Respondents also agree that students should not rely solely on supervisors, because the true reason on the success of quality thesis writing is fully under the post graduates' own accountability and responsibility. Keywords: Supervisory Relationship, Postgraduate Student, Case-Study
\end{abstract}

\section{Introduction}

The journey as a post graduate student is a continuous learning process whose momentum is unable to be fully controlled because its existence consists of various allegations and challenges from every aspect. Among the challenges that often affect the experience of first-year students are the bilateral relations with their supervisors (Hamshire, Barrett, Langan, Harris, \& Wibberley, 2017), support (Ooms, Fergy, Marks-Maran, Burke, \& Sheehy, 2013) expectations in learning (Mikkonen, Elo, Kuivila, Tuomikoski, \& Kaariainen, 2016), competitiveness and high confidence in academic reading, writing, research and skills (Sidhu, Kaur, Chan, \& Lee, 2015). In this case, supervisors as a mentor to the novice student play a key role in guiding, advising, ensuring 
scientific quality of writing as well as providing emotional support (Lessing \& Schulze, 2002), moral support as well as professional learning to students (Shanks, 2017). Quality of supervision depends on the quality of interaction between post graduate student-supervisor and the extent to which supervisors and students understand their roles and responsibilities (National University of Malaysia, 2015).

Thus, underprivileged students can enhance the development of learning 386nalysed386 and exploration (Craig, Allen, Reid, Riemenschneider, \& Armstrong, 2013) through the relationship between mentor and protégé (Veale \& Wachtel, 1996). This process will be more effective when there is similarity in the relationship between students and supervisors who serve as mentors (Erdem \& Aytemur, 2008).

Supervision or supervisory relationship is a dynamic relationship allowing two professionals to share their professional and personal expertise and experience while encouraging, educating and administrating the essential qualities, capabilities, strengths and weakness for the psychological, professional and social wellbeing of the supervisee. It is a relationship which is based on trust and confidence; understanding and communication skills and openness and honesty. The relationship between postgraduates and supervisors is a complex form of relationship. The satisfaction of both parties in the relationship can contribute to the success of thesis writing (Prazeres, 2017). Although the supervision process is viewed as a stressful experience (Sidhu et al., 2015), the performance shown by the supervised student reflects its effectiveness (Jafree, Whitehurst, \& Rajmohan, 2016; Sze, 2001). Thus, students are able to graduate according to the designated period.

Current study indicates that effective supervision influences the quality of the PhD and its ultimate success or failure (Gill and Burnard, 2008). A variety of factors influences the relationship between supervisor-supervisee, such as the characteristics of the individuals, institutional environment, roles and responsibilities, and the supervisory style (Orellana et al., 2016). Within the context of the current review, much of the literature was focused on supervisor's feedback (Phelps, 2013), supervisor's skills and interventions such as active listening, reflection of feeling, and self-disclosure (Ladany, Mori, \& Mehr, 2013) and as well as the supervisory relationship are some of the variables regarding quality supervision. However, most of the studies focus on the effectiveness of supervision and the general provision of research about the supervisory relationship from the perspective of the informants is still lacking. This research was directed both with a focus on the student's supervisory experiences, and with material clearly from a student's perspective.

The selection of supervisors is usually performed by students and supervisors which is then determined by the faculty that has different impacts on students (Malik \& Malik, 2015). This is linked to the supervisor's commitment and dedication (Creighton, Creighton, \& Parks, 2010), although supervisors are not the only factor that determines any post graduate students' success. The process of generating knowledge will also be effective when there is a closer relationship and mutual respect as well as good supervisory interaction between the post graduate students and the supervisors either in formal setting or informal setting (Ensher \& Murphy, 2011). Therefore, 
this study is conducted to explore the experience, guidance and supervision of the first semester graduate students, based on the following research questions:

(1) What is the students' perspective on the role of their supervisor?

(2) How do they undergo supervision?

(3) What are the assessments to pass supervisory process?

\section{What is Supervisory Relationship?}

Supervision is a supportable interpersonal and interactional relationship between two potent professional within the same workplace. It is a system in which an experienced and expertise in a specific field advises and guides someone new to that particular field or in the middle of a career development transition phase. It is widely agreed that establishing and sustaining the supervisory relationship is important for successful supervision (Beinart, 2014). Due to boundaries of the supervisor-supervisee relationship, there is great variation in how supervisors approach supervision (Stone 1994). Glauser (1984) suggested that upward communication is ostentatious not only by characteristics of the communicator, the message, and the organizational context, but also by characteristics of the supervisor-subordinate relationship. A "better" supervisorsubordinate relationship alleviates upward information flow. Saunders, Sheppard, Knight, and Roth (1992) found that workers who found their supervisor to be transparent and sensitive were more willing to express opinions and suggestions related to their job. Once employees perceived that their managers were open to feedback, rational, responsive and welcoming, greater voice behaviors were introduced (Morrison, 2014). Thus, supervision is a method used to train the supervisee such post-graduate student to attain the various skills required for the particular task while maintaining a healthy, friendly, safe and a conducive learning environment for students.

Supervisory relationship is affected by personal characteristics and both the supervisor and the supervisee. The relationship is also influenced by other variables such as personal clashes, poor communication skills, lack of enthusiasm and dedication, problem supervisee or supervisor, lack of commitment and trust. Such interpersonal disputes affect the relationship greatly and eventually contribute to a toxic working relationship. A misunderstanding created due to lack of communication, appropriateness of the techniques using in various dental processes, amount of time spent to discuss goal and direction, willingness to resolve conflict and mutual trust, respect and confidence plays a significant role.

Trust was described as an individual's belief in, and willingness to act on the basis of, the words, actions, and decisions of another (Lewicki \& Wiethoff, 2000). Trust represents relationship quality as it helps to reduce uncertainty in complex human relationships (Bruhn, 2003). It is a basis for interpersonal relationships and a foundation for organizational relationship stability (Hulten, 2007). There are two main areas where confidence comes into play: professional and personal. Academic relationships are usually task-oriented and goal-oriented, whereas personal relationships are more emotional and apparently focus on the relationship itself. In addition to achieving the long-term goals, short-term and immediate goals from this relationship are also expected to be achieved. In student-supervisor relationships, research success is a key focus. 
Prior studies have shown that some variables play an active role in the formation of strong relationships. According to findings of these studies, supervisory relationship was influenced by supervisor's style (Wilson, \& Que, 2013), self-disclosure (Ladany \& Lehrman-Waterman, 1999), and feedback (Hughes, 2012), supervisee's cognitive level (Fong, Borders, Ethington, \& Pitts, 1997) and anxiety of performance and monitoring (Bradley \& Ladany, 2001). In addition, Ladani (2013) stated that several studies found supervisors are required to routinely assume the role of teachers for the first time. First-time supervisees also expected their supervisors to be warm, embraced, respectful, truthful, and explain their supervisory expectations and responsibilities at the start of the relationship (Meydan \& Denizli, 2018).

\section{Methodology}

This study is a qualitative case study aimed at exploring the atmosphere of interaction of a group of individuals in an institution (Yin, 2013). Thus, semi-structured interviews and document analysis were used for data collection. The interview sessions were recorded using a digital recorder and then transcribed into transcripts in verbatim form. The informants sought permission before the interviews. Because videotaped sessions could be considered invasive, digital audio recorders were used to record in-depth interviews. Digital recorders were used to allow data management and translation from the verbatim text. Beside the recording and utilization of the interview guide, document analysis is done on the report for the experiences written by all four participants on the process of establishing relationships with their respective supervisors. Documents examined by researchers are referred to experience reports written by the four respondents which facilitated understanding of the informants' experiences in a more unobtrusive manner. Document analysis can be used as additional information to support the interviews undertaken by researchers (Othman, 2007; Creswell, 2012). During data collection, respondents were interviewed three times and each interview sessions took between 40 minutes to an hour. Interviews were transcribed and analysed through a constant comparative method, following these four stages; firstly, we comparing incidents applicable to each category. Secondly, we integrating categories and their properties. Thirdly we delimiting the theory, and finally writing the theory (Lincoln \& Guba, 1985). We read the verbatim transcripts several times in the beginning, described the cases and compared the incidents simultaneously. The cases compared were then registered, categorized and compared in different categories. We constantly compared the data and committed to finding new patterns by coding them into meaningful categories and themes.

In order to ensure the validity and reliability of the study, triangulation data was conducted (Creswell, 2013). The reliability and trustworthiness of the results was assured through the triangulation of the researcher, involving multiple researchers in the process. We collected the data, independently analysed it and compared our findings. One technique used was an audit trail, where we reported steps taken during the analysis, including how data was collected, how categories were created, and how decisions were made on certain topics, thoughts, ideas and issues (Merriam, 2010). Several guidelines were observed in conducting the study, such as when we interacted in the research sense, we played the role of the research instrument throughout 
the data collection. We also chose the correct techniques for data collection, were sensitive to non-verbal communication throughout interviews and constantly processed and analysed the data as suggested by Guba \& Lincoln, (1981). Compassion, alertness, sensitivity and good communication skills were also practiced all through the research process. The respondents were named Respondent 1, Respondent 2, Respondent 3 and Respondent 4.

\section{Results}

The results showed that the development of supervisory relationship was mainly affected from supervisor- and supervisee-related variables. The constant comparative method utilized in the data analysis resulted in the generation of six themes that were the priority of graduate students in creating compatibility while establishing supervisory relationships with supervisors. These aspects are the alignment of tendencies and interests, frequency of time, effective communication, trust, mutual respect, and timelines. The common structures of the findings were presented in Figure 1.

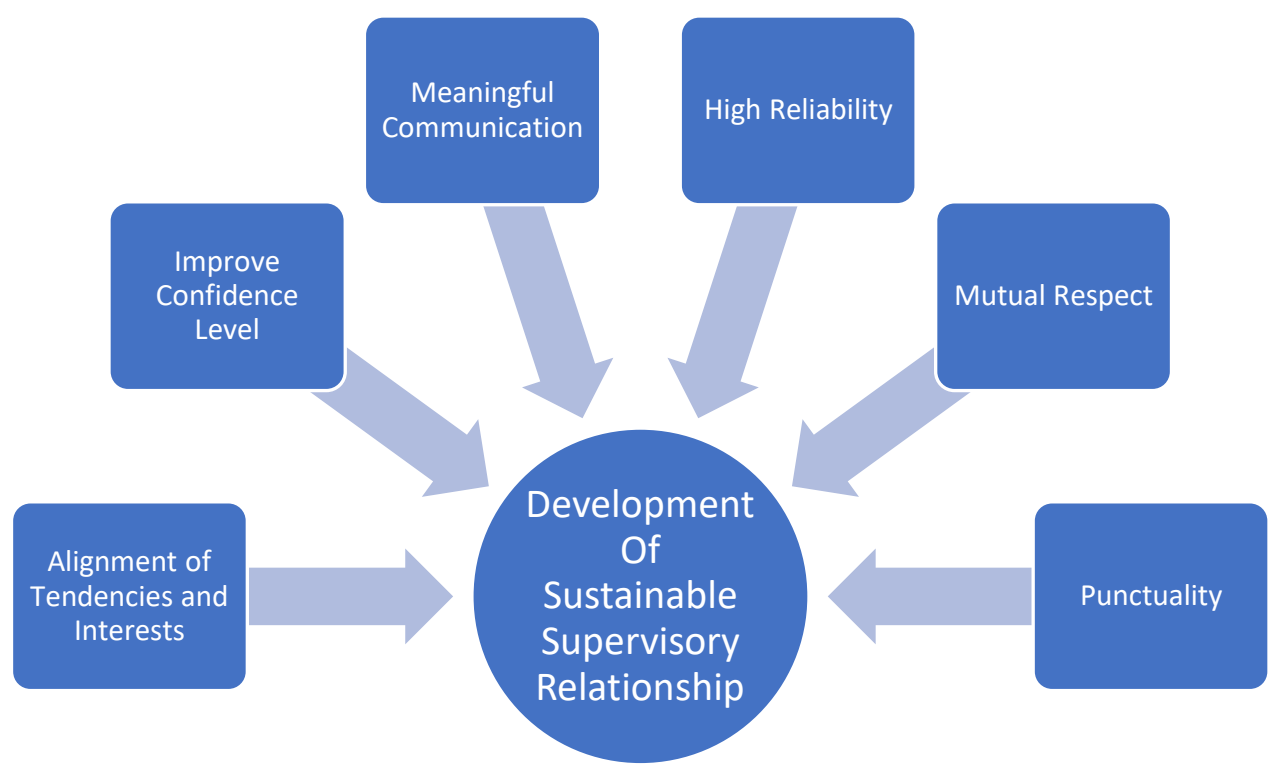

Figure 1. Common Structure of Informants' Supervisory Relationship Experiences

\section{Alignment of Tendency and Interests}

All respondents agreed on the first meeting with the supervisor, that the research proposal submitted previously was not immediately read by their supervisors. The supervisor only requested the respondents to summarize the study. Proposed proposals were not agreed immediately but most supervisors suggested that respondents found information related to their previous writing. In this case, respondent 1 states that: 
INTERNATIONAL JOURNAL OF ACADEMIC RESEARCH IN BUSINESS AND SOCIAL SCIENCES

Vol. 9, No. 11, November, 2019, E-ISSN: 2222-6990 @ 2019 HRMARS

"... the supervisor instructed me to search for his previous writings and examine the scope of his writings ... what theories to add in your proposal ..."

Respondents 2 added that the importance of supervisory knowledge about the aspects that are the interests of the students is very important.

"... effective supervisors are knowledgeable and have the skills in the field of research carried out by students. If both are incompatible, it is best to switch supervisors, this is because it may be difficult to seek proper co-operation. Perhaps students and supervisors have certain advantages. The disadvantage of choosing a topic that is not familiar to their supervisors could be dangerous as the supervisor might not have interest in reading your work and could not be bothered to go through what you have done."

Every respondent agree that compatibility can be established if the supervisee's interest and the supervisors' interest is mutual. Two of the respondents acknowledged that they have done little research on the topic that are of interest of their supervisors instead of their own, as the consequences of not choosing the supervisor arbitrarily.

For example, respondents 3 conducted a preliminary survey of potential lecturers to be supervisors and sent a research proposal and profile via email. But the result was disappointing when none of the survey questions were answered. However, the respondents stated that they were excited as soon as the application to appoint a supervisor of own choice was accepted. However, they are still uncertain whether the selected supervisors can accept the proposed research.

\section{Improve the Stage of Self Confidence}

Another significant result of this study was that, despite of the professional developmental level of supervisees, they were mostly nervous at the beginning of the supervisory relationship. The respondents also admit that they felt as though they had lost their way during their first week after registration. The initial stage as a post graduate student full confusion and tension. The change from work to learning is an unpredictable experience.

Respondent 4 questioned his decision to undergo postgraduate studies.

"... I'm not sure I'm making the right decision to further my studies. I still have not had the opportunity to meet with the supervisor. I'm not sure what to do. It is an experience that might dampen my spirit ... "

However, after the first meeting with the supervisor, respondent 4 felt the level of confidence had increased and the results of his initial discussion with his supervisor was enlightening as he now know how to search for the answers to some of his questions.

"... Previously, I was very disappointed when all the emails sent were ignored and I did not get any feedback. I was very disappointed and felt less excited but after the first meeting. Everything changed ..." 
The same experience is shared by respondent 3 who agreed that his level of confidence also increased after several meetings with his supervisor and he begins to believe in himself. Respondent 3 states:

"... I'm sure I can continue this semester well. I have made the right decision by selecting him as a supervisor and getting good feedback on my research proposal. I'm ready to move forward. Before this, I was not sure who the supervisor was and the supervisor's duty. I also feel uncertain about my direction before I begin my studies. First of all, I did not understand, but after several discussions I started to see the direction ... I started to understand my supervisor ... ".

Respondent 2 also acknowledged that he always tried to understand his supervisor closely. He also tried to understand the approach and type of research done by his supervisor. He believes this can help the process of identifying supervisors to assist in the process of study. He also stated:

"... if we do not really know the supervisor, how do we get the knowledge from him ... we cannot just hear what the supervisor says ... spend more time and look at how he works ..."

\section{Meaningful Communication}

Human relations are based on good and meaningful communication. Meaningful to students refers to constructive feedback to enable students to learn new knowledge and skills on research methods to enable them to move forward. However, negative feedback creates confusion and disappointment as mentioned by respondent 1 :

"... Although the feedback provided was honest, I did not understand some of the meanings and I felt that it was a bit disappointing. I am sure that all feedbacks are positive and I appreciate the willingness of the supervisors to spend time sharing their experiences positively. However, negative feedbacks can damper my inner motivation ... "

All respondents agree that excellent relationship means that meaningful communication and the barriers in communication can negatively affect both students and supervisors.

\section{High Reliability}

Relationships between supervisors and students need to be based on mutual trust. This is acknowledged by respondent 2 stating that the supervisory relationship established on the basis of reliability creates a closer relationship and the supervisor becomes a major reference when question arises. Respondent 2 mentions:

"I believe that what is being proposed is the best and I try my best to conduct whatever needs to be done.."

The same response was acknowledged by respondent 3 through his statement which illustrates his belief pertaining his supervisor: 
INTERNATIONAL JOURNAL OF ACADEMIC RESEARCH IN BUSINESS AND SOCIAL SCIENCES

Vol. 9, No. 11, November, 2019, E-ISSN: 2222-6990 @ 2019 HRMARS

"... my supervisor is very good as he takes time to explain everything explicitly. Although he was a busy person, he was still willing to excuse himself to meet up for some brief explanation. I now can see the view from the point of his perspective ..."

However, the experiences experienced by respondent 4 are slightly different. His acquaintance who had graduated from the previous semester had stated something negative about the supervisor he had chosen.

"SV became a problem to my friend who is currently doing PhD, where his supervisor repeated the viva voce twice. His SV took a very long time to respond to emails and was very difficult to get in touch with him. There was once a friend of mine who had to wait three hours outside the room just to get a signature which should only take three seconds to be done... "

However, the aforementioned is just hearsay without any concrete evidence. Respondent 4 decided to meet with his supervisor without being influenced by other people's opinions, and it appears that his judgment to remain with his decision is accurate.

\section{Mutual Respect}

Demonstrating appreciation is an important element in maintaining interpersonal relationships. Individuals who are courteous and have self-respect are important and very crucial in the context of maintaining relationships with one another such as respecting the views and thoughts of others, and selflessness without any regards to rank and position. Supervisors should respect students, and vice versa. Respect should be mutual without any age limit. Respondent 1 in his confession states:

"... My supervisor is younger, but his knowledge is higher ... despite being a bit clumsy at the first meeting, but I still respect him .... this mutual respect makes us comfortable to talk to each other ..."

All respondents also agreed that they first obtained the background of potential supervisors' backgrounds in order to guide them and learn about the communicating for the first time as a sign of respect.

\section{Punctuality}

Another approach applied by all respondents while building a supervisory experience with supervisors is to adhere to timeliness through proper time management. Good time management allows the student to indirectly comply with the appointments that have been arranged and meet at the agreed upon time. Thus, good time management depicts that every individual who wishes to succeed in life are able to manage their schedule systematically. Time plays an important role in a research conducted. Systematic and efficient timesharing and timeconsuming with proper activity reflects high moral values in a timely moral context. In this case, respondent 2 states:

"... I'm disappointed because my supervisor seldom shows up on time. I understand he has a tight schedule and maybe I need to get used to this situation ... " 
Respondent 3 also stated:

"... The always on-time supervisors are idiosyncrasies, but as students, I am also responsible for always delivering timely deliveries. Human beings, each with their own uncontrollable control ... try their best ..."

"...As a student I am responsible for being there on time. It is normal for hindrance to occur every now and then. Sometimes it is out of our control. I am trying my best to deliver whatever possible..."

Additionally, as students who just started studying, all respondents admitted that graduates should always be prepared with criticisms related to the writing given by the supervisor. The criticisms are not intended to reduce their motivation, but every criticism should be accepted positively with useful guides, especially in writing the article later. Students should also submit all written work to the supervisor at the time specified in the next meeting. Respondents also state that it is their responsibility to ensure there is suffice time for writing purposes so that supervisors have sufficient time to review and correct errors in their writing.

All respondents agreed that positive relationship between supervisors and students are very helpful in their research and learning. However, they are still in doubt as to how well this will be able to help them to produce good theses and they were also unsure of what kind of help the supervisor could provide and whether each supervisor provides the same assistance to all students under the supervision. In this case, respondents 1 states:

"... my friend's supervisor is very helpful. Students under his supervision are mentored to seek opportunities on second meeting and examples proposals by past students are shown. My friend was also invited to participate in the seminar as an observer and as an early exposure ... his supervisor was very helpful, but his expertise did not fit my study ... "

The second respondent was advised by his supervisor to search the internet when the respondent requested for a sample of research proposal. The respondent was quite disappointed but accepted the advice of his supervisor. Respondent 4 mentions:

"... I'm not sure how much help can be given by the supervisor other than reviewing and suggesting improvements in research writing ... there are supervisors participating in focus group interviews when students are piloting a pilot study in a case study. He even helped his students to conduct an interview for the first time. I'm not sure whether my supervisor that I choose will help me that way ... at least he can introduce me to his senior students who are in the process of collecting data so that I can get an early exposure before my turn will come... "

\section{Discussion}

The study aims to explore the experience of building relationships between postgraduate students and supervisors through a case study approach. This study employed a qualitative study in answering the question of whether a healthy relationship between supervisors and graduates is able to support research and learning of post graduate students. Although there are some 
limitations in the study such as the selection of graduate students in only one university and the students are in the same faculty, this study helps students to progress with confidence in building better supervisory relationships with supervisors. The limitations of this study also examine the experience of the graduate student's perspective without taking into account the supervisor's experience.

The first-year experience of graduate students at any university is a critical period as graduate students are not only intellectually focused, but also face the dilemma in maintaining personal relationships, leaving career, lifestyle, health and self-development. Overall research findings indicate that respondents are not confident of meeting their supervisors for the first time as they are unsure on the nature of an academic discussion. The findings also show that the expertise and interest of supervisors in the field of research chosen by the respondents is significant in determining the success of the study to be undertaken by the graduate students. Respondents of the study also agreed that they were unsure pertaining the impression of the supervisors. Supervisors should help prepare students with self-learning skills specifically to build confidence among postgraduate students (Sidhu, Kaur, \& Fook, 2016). Rhodes (2005) and DuBois et al. (2011) suggested learning outcomes from mentors that could contribute to the development of socioemotional, cognitive and protege identity. Previous studies also show that when students gain experience from positive support, students will be able to build their resilience and confidence and become more competitive. In this context, supervisors are encouraged to establish supervisory relationships by addressing supervisors ' developmental needs.

Time management is also an important aspect in student-supervisor relationships because proper time management can display student's ability and credibility in managing various other responsibilities (Moir \& Bloom, 2003). Time-management skill is crucial in the life of a graduate student. Effective time management practices need to be applied by students so that they are wise in monitoring and using time well to achieve success and satisfaction as students.

Students also look forward to and appreciate constructive feedback from supervisors (Webb \& Shakespeare, 2008). Learning through the practice is also a means of rapid learning and observation (Bandura, 1977), and to observe supervisory actions, the frequent time spent between supervisors and graduate students should be practiced. The process of learning by observing the behavior of others is a modeling process and in parallel with the Social Learning Theory highlighted by Bandura (1977), which outlines four key elements in learning that begins with observation, followed by considering what is observed, reproducing images and information which is observed and finally reinforcement and motivation. The learning process through these behaviors is also closely linked to the self-motivation of graduate students when they are assisted by the input and role played by supervisors.

\section{Summary, Suggestions and Implications}

Based on the findings, although contextual and limited, the following recommendations are proposed. Students and supervisors should play their respective roles and ensure their relationship is in a comfortable state. The research findings confirmed that there is no best way to teach the art of strengthen relationships with others especially supervisors. Good relationships 
are derived from a combination of personal and professionalism. Moreover, mutual care and understanding are also one of the factors that could strengthen the relationship between students and supervisors. Effective communication between students and supervisors is also a vital element of supervision. Openness and honesty in communicating provide a positive communication between the student and the supervisor. The above elements provide a win-win situation for both the student and supervisor in discussing the relevant matters. The responsibility of good supervisors should be based on practicality, efficiency and honest ways and approaches to produce successful students who can yield good research. Other than that, to achieve sustainable supervisory relationship, the student must frequently update the development progress of the thesis to supervisors to continue communicating consistently with the supervisor. Students should avoid contacting supervisors only when in need. Prior confirming for an appointment, the students must prepare all the tasks requested by the supervisor and check all the spellings, the title on the correct table and pages to facilitate the supervisor to review student's writing results.

This study has positive implications for future graduates in establishing good supervisory relationships with their respective supervisors and thus becoming the catalyst for the development of professional postgraduate students. In addition, the university administration should also take a more comprehensive approach to the supervision of graduate students such as involving all parties at every level starting from the graduate, faculty, department, lecturer to supervisor. The university is also advised to provide a special channel for graduates to make references if there are any problems arising from the student-supervisor relationships to avoid any recurring problems between the student and the supervisor, which can be resolved by a third party through effective discussion pertaining the problem. In other words, the holistic support provided by the administration of the university and supervisors may reduce the burden of the student and help transformation that can lead to the student's success (Porteous \& Machin, 2017). This study can also be used as a guide to graduate students on what needs to be done in maintaining a positive relationship with their supervisor. Therefore, it is important for the students to spend as much time as possible with their supervisors. When viewed as a whole, the experience gained by the respondents in this study varies. There are varied moments during the introductory phase of the relationship, nonetheless, there is a meaningful lesson in the pursuit of a better phase in the next semester. It is recommended that every graduate student regardless of level of studies, should maintain a good relationship with their supervisor, and respect the supervisor in whatever circumstances regardless of his position and rank. Graduates should place themselves as someone who want to acquire knowledge by befriending his or her own supervisor. Graduate students should demonstrate a professional way of working with supervisors so that supervisors are more comfortable working with the students.

Consequently, cooperation from all stakeholders; students, supervisors, lecturers and the university itself can assist the development of graduates' learning. If everyone plays their respective roles in accordance with the guidelines provided, this collaboration will benefit the stakeholders. Supervisors should establish a healthy supervisory culture to help students towards continuous learning and enhance their confidence in learning independently. Students 
must also master the skills of continuous learning to move themselves confidently in a challenging world of research. In addition, time management can also provide benefits to the graduates as students, and to increase productivity in their work. Case studies allow for in-depth understanding of both the outcomes and processes related to the experience of establishing a supervisory relationship between post-graduates and supervisors from the perspective of novice students, and provide rich, contextual data that empirical instruments alone often cannot capture. The results of such case studies can help to identify existing strengths and weaknesses of relationship that exists between student and their supervisors.

Finally, there are limited studies regarding supervisory relationship for supervisees in only one faculty in Malaysia public university. Therefore, for future studies, it is recommended that, in order to understand the supervisory relationship experiences of supervisees at different developmental levels, different research methodologies should be used and more data should be collected from various universities.

\section{Conclusion}

This research has theoretical and contextual contributions. In terms of supervision theory, this study offers a value added to supervision variables that are salient to the supervision processes. The findings of this study demonstrate that a sustainable supervisory relationship acts as an effective predicting variable of post graduate advancement in the development of professional and talented postgraduate students. Very little has been theoretically written about supervisory relationship in particular, much less regarding the interplay among the variables presented. Hence, supervision theorists may do well to consider these variables in the context of developing sustainable supervisory relationship models.

This study focuses on the willingness of lecturers and students to create a collaborative network to enhance the understanding of a complex phenomenon that is inevitable in a supervisory relationship. Contextually the findings of this study contribute to the development of socioemotional, cognitive and learning opportunities that are more meaningful to PG students who are just starting their studies. This relationship is as important as the beginning of a graduate's journey of excellence. The results of this study can also serve as a guide for stakeholders in producing professional students at various levels in public universities. Last but not least, despite the challenges of establishing supervisory relationships, the guidance, motivation and encouragement provided by the supervisor ultimately helped post graduate students to maximize their potentials to their full capacity.

\section{References}

Bandura, A. (1977). Self-efficacy: Toward a unifying theory of behavioral change. Psychological Review, 84(2), 191-215. https://doi.org/10.1037/0033-295X.84.2.191

Beinart, H. (2014). Building and sustaining the supervisory relationship. In C. E. Watkins, \& D. L. Milne (Eds.), Wiley international handbook of clinical supervision (pp. 257-281). MA: Wiley Blackwell.

Craig, C. A., Allen, M. W., Reid, M. F., Riemenschneider, C. K., \& Armstrong, D. J. (2013). The 
INTERNATIONAL JOURNAL OF ACADEMIC RESEARCH IN BUSINESS AND SOCIAL SCIENCES Vol. 9, No. 11, November, 2019, E-ISSN: 2222-6990 @ 2019 HRMARS

Impact of Career Mentoring and Psychosocial Mentoring on Affective Organizational Commitment, Job Involvement, and Turnover Intention. Administration \& Society, 45(8), 949-973. https://doi.org/10.1177/0095399712451885

Creighton, L., Creighton, T., \& Parks, D. (2010). Mentoring to degree completion: Expanding the horizons of doctoral prot??g??s. Mentoring and Tutoring: Partnership in Learning. https://doi.org/10.1080/13611260903448342

Creswell, J. (2013). Qualitative, quantitative, and mixed methods approaches. Research Design, 1-26. https://doi.org/10.2307/3152153

Ensher, E. A., \& Murphy, S. E. (2011). The Mentoring Relationship Challenges Scale: The impact of mentoring stage, type, and gender. Journal of Vocational Behavior, 79(1), 253-266. https://doi.org/10.1016/j.jvb.2010.11.008

Erdem, F., \& Aytemur, J. O. (2008). Mentoring - A relationship based on trust: Qualitative research. Public Personnel Management, 37(1), 55-65. https://doi.org/10.1177/009102600803700104

Fong, M. L., Borders, L. D., Ethington, C. A., \& Pitts, J. H. (1997). Becoming a counselor: A longitudinal study of student cognitive

Glauser, M. J. (1984). Upward information flow in organizations: Review and conceptual analysis. Human Relations, 37, 613-643.

Gill, P., and Burnard, P. (2008) The student-supervisor relationship in the PhD/doctoral process. British Journal of Nursing 17(10): 668-671.

Guba, E., \& Lincoln, Y. (1981). Effective evaluation. San Francisco: Jossey-Bass

Hamshire, C., Barrett, N., Langan, M., Harris, E., \& Wibberley, C. (2017). Students' perceptions of their learning experiences: A repeat regional survey of healthcare students. Nurse Education Today, 49, 168-173.

Hughes, J. (2012). Practical aspects of supervision: All you ever wanted to know but were too afraid to ask. In I. Fleming \& L. Steen (Eds.), Supervision and clinical psychology: Theory, practice and perspectives (pp. 184-206). Hove, UK: Routledge.

Hutt, C. H., Scott, J., \& King, M. (1983). A phenomenological study of supervisees' positive and negative experiences in supervision. Psychotherapy: Theory, Research and Practice, 20(1), 118-123.

Jafree, D. J., Whitehurst, K., \& Rajmohan, S. (2016). How to approach supervisors for research opportunities. Annals of Medicine and Surgery, 10, 110-112. https://doi.org/10.1016/j.amsu.2016.01.022

Ladany, N., Mori, Y., \& Mehr, K. E. (2013). Effective and ineffective supervision. The Counseling Psychologist, 41(1), 28-47.

Lessing, A., \& Schulze, S. (2002). Postgraduate supervision and academic support: students' perceptions. South African Journal of Higher Education, 16(2), 139-149. https://doi.org/10.4314/sajhe.v16i2.25253

Lewicki, R. J., \& Wiethoff, C. (2000). Trust, Trust Development, and Trust Repair. In. M. Deutsch \& P.T. Coleman (Eds.), The handbook of conflict resolution: Theory and practice (p. 86107). San Francisco, CA:Jossey-Bass. 
INTERNATIONAL JOURNAL OF ACADEMIC RESEARCH IN BUSINESS AND SOCIAL SCIENCES Vol. 9, No. 11, November, 2019, E-ISSN: 2222-6990 @ 2019 HRMARS

Lizzio, A., Wilson, K., \& Que, J. (20). Relationship dimensions in the professional supervision of psychology graduates: Supervisee perceptions of processes and outcome. Studies in Continuing Education, 31(2), 127-140

Meydan, B., \& Denizli, S. (2018). Turkish undergraduate supervisees' views regarding supervisory relationship. Eurasian Journal of Educational Research, 74, 1-24

Merriam, S. B. (2010). Qualitative case studies. In International Encyclopedia of Education (pp. 456-462). https://doi.org/10.1016/B978-0-08-044894-7.01532-3

Malik, S. A., \& Malik, S. A. (2015). Graduate school supervisees' relationships with their academic mentors. Journal of Applied Research in Higher Education, 7(2), 211-228. https://doi.org/10.1108/JARHE-07-2013-0032

Mikkonen, K., Elo, S., Kuivila, H.-M., Tuomikoski, A.-M., \& Kaariainen, M. (2016). Culturally and linguistically diverse healthcare students' experiences of learning in a clinical environment: A systematic review of qualitative studies. International Journal of Nursing Studies, 54, 173-187. https://doi.org/10.1016/j.ijnurstu.2015.06.004

Moir, E., \& Bloom, G. (2003). Fostering Leadership through Mentoring. Educational Leadership, 60(8), 58-60. Retrieved from http://www.ascd.org

Morrison, E. W. (2014). Employee voice and silence. Annual Review of Organizational Psychology and Organizational Behavior, 1, 173-197

Murphy, N. A., \& Wibberley, C. (2017). Development of an academic identity through PhD supervision-an issue for debate. Nurse Education in Practice, 22, 63-65. https://doi.org/10.1016/j.nepr.2016.12.002

Ooms, A., Fergy, S., Marks-Maran, D., Burke, L., \& Sheehy, K. (2013). Providing learning support to nursing students: A study of two universities. Nurse Education in Practice, 13(2), 89-95. https://doi.org/10.1016/j.nepr.2012.07.011

Orellana, M., Darder, A., Pe'rez, A., and Salinas, J. (2016) Improving doctoral success by matching PhD students with supervisors. International Journal of Doctoral Studies 11: 87103.

Phelps, D. L. (2013). Supervisee experiences of corrective feedback in clinical supervision: A consensual qualitative research study. (Unpublished doctoral dissertation). Marquette University

Porteous, D. J., \& Machin, A. (2017). The lived experience of first year undergraduate student nurses: A hermeneutic phenomenological study. Nurse Education Today. https://doi.org/10.1016/j.nedt.2017.09.017

Saunders, D. M., Sheppard, B. H., Knight, V., \& Roth, J. (1992). Employee voice to supervisors. Employee Responsibilities and Rights Journal, 5, 241-259

Shanks, R. (2017). Mentoring beginning teachers: professional learning for mentees and mentors. International Journal of Mentoring and Coaching in Education, 6(3), 158-163. https://doi.org/10.1108/IJMCE-06-2017-0045

Sidhu, G. K., Kaur, S., Chan, Y. F., \& Lee, L. F. (2015). Taylor's 7th Teaching and Learning Conference 2014 Proceedings, 529-545. https://doi.org/10.1007/978-981-287-399-6 
Sidhu, G. K., Kaur, S., \& Fook, C. Y. (2016). Postgraduate students' level of dependence on supervisors in coping with academic matters and using digital tools. Journal of Computing in Higher Education, 28(3), 370-388. https://doi.org/10.1007/s12528-016-9121-1

Silverman, D. (2004). Qualitative Research: Theory, Method and Practice. Qualitative Research. https://doi.org/10.1073/pnas.0703993104

Sze, D. (2001). Effective Student-centred PhD Supervision from a Social Constructivist Viewpoint. Learning, 1-6.

Universiti Kebangsaan Malaysia. (2015). Garis panduan penyeliaan pelajar siswazah 2015, 1-32.

Veale, D. J., \& Wachtel, J. M. (1996). Mentoring and coaching as part of a human resource development strategy: an example at Coca-Cola Foods. Management Development Review, 9(6), 19-24. https://doi.org/10.1108/09622519610151615

Webb, C., \& Shakespeare, P. (2008). Judgements about mentoring relationships in nurse education. Nurse Education Today, 28(5), 563-571. https://doi.org/10.1016/j.nedt.2007.09.006

Yin, R. K. (2013). How to Start Your Analysis, Your Analytic Choices, and How They Work. Case Study Research: Design and Methods, 127-164. https://doi.org/10.1111/bjd.13028 